\title{
Gerenciamento da Cadeia de Suprimentos e Relacionamento nas Agências de Viagens em Santa Catarina
}

\section{Supply Chain Management and Customer and Supplier Relations in Santa Catarina's Travel Agencies}

\section{Gerenciamiento de la Cadena de Suministro y Relacionamiento en las Agencias de Viajes en Santa Catarina}

Carlos Alberto Tomelin ${ }^{1}$

Doris Van De Meene Ruschmann ${ }^{2}$

Diva de Mello Rossini ${ }^{3}$

\begin{abstract}
Resumo
Este artigo identifica e analisa a gestão da cadeia de suprimentos e o relacionamento nas agências de viagens a fim de agregar os diferenciais competitivos aos seus serviços, tão importantes nas organizações que buscam consolidar-se perante seus clientes atuais e potenciais. No estudo realizado, utilizou-se a análise dos dados quantitativos e qualitativos, uma vez que as relações entre as variáveis - gestão da cadeia de suprimentos e serviços, adotada pelas agências de viagens, e sua relação com os fornecedores e clientes -, foram analisadas e quantificadas de forma a traçar comentários e discutir tal situação entre os envolvidos. A população alvo da pesquisa foi composta por todas as agências filiadas à Associação Brasileira de Agências de Viagens - ABAV, seccional de Santa Catarina. A amostragem de identificação da população considerada foi intencional, envolvendo as 60 Agências de Viagens e Turismo que atuam no turismo emissivo e receptivo, características de prestação de serviços necessárias para a presente pesquisa. Utilizou-se a técnica multivariada chamada de análise de agrupamentos ou de cluster, organizada de forma a compreender a situação das agências e entender a complexidade das relações que coexistem entre as agências de viagens e turismo e os participantes da cadeia. Os resultados levaram a concluir que as relações entre os agentes de viagem, seus clientes e fornecedores são superficiais, restringindo-se apenas aos aspectos comerciais da transação, comprometendo uma relação mais personalizada, que contribuiria para a finalização do modelo de gestão tradicional, imposta pelos fornecedores atuais.
\end{abstract}

Palavras-chave: Gestão da Cadeia de Suprimentos e Serviços; Agências de Viagens; Clientes e Fornecedores; Relacionamento.

\footnotetext{
${ }^{1}$ Doutor em Administração e Turismo pela Universidade do Vale do Itajaí (Univali). Mestre em Turismo e Hotelaria; Especialista em Turismo e Hotelaria; Marketing; e Metodologia do Ensino Superior. Graduado em Turismo pela PUC/RS. Diretor do Centro de Ciências Sociais Aplicadas: Comunicação Turismo e Lazer da Univali. Brasil. tomelin@univali.br

${ }^{2}$ Doutora e Mestre em Ciências da Comunicação pela Escola de Comunicações e Artes da Universidade de São Paulo (ECA-USP). Graduada em Turismo pela ECA-USP. Docente e Pesquisadora do Programa de Mestrado Acadêmico em Turismo e Hotelaria da Univali. Brasil. d.ruschmann@univali.br

${ }^{3}$ Doutora em Administração e Turismo pela Univali. Mestre em Engenharia de Produção pela Universidade Federal de Santa Catarina (UFSC). Graduada em Arquitetura e Urbanismo pela Univali. Professora do Curso de Arquitetura e Urbanismo e Design de Interiores da Univali. Brasil. divarossini@univali.br
} 


\begin{abstract}
This article identifies and analyzes the management of the supply chain and customer and supplier relations in travel agencies, in the search for ways of adding competitive advantages to their services, which are so important in organizations seeking to become consolidated with their actual and potential clients. The proposed study uses analysis of quantitative and qualitative data, as the relations between the variables - management of the supply and services chain, adopted by the travel agencies and their relations with suppliers and clients were analyzed and quantified in order offer comments and discusses the situation with those involved. Multivariate cluster analysis was used to understand the agencies' context, and the complexity of the relations that coexist between travel and tourism agencies and the participants of the chain. The target population of this research was composed of all agencies affiliated to the Brazilian Association of Travel Agencies - ABAV sectional Santa Catarina. The sample population identification was considered intentional, involving 60 agencies Travel and Tourism working in emissive and receptive tourism, characteristics of service required for this search. The results are as follows: the relations between travel agencies, their clients and suppliers, are superficial, being restricted to purely commercial aspects of the transaction, which creates a barrier to a more personalized relationship that would help do away with traditional management model, imposed by current suppliers.
\end{abstract}

Keywords: Management of Supply and Service Chain; Travel Agencies; Customers and Suppliers; relationship.

\title{
Resumen
}

Este artículo identifica y analiza la gestión de la cadena de suministro y el relacionamiento en las agencias de viajes a fin de agregar a sus servicios los diferenciales competitivos tan importantes en las organizaciones que buscan consolidarse ante sus clientes reales y potenciales. En el estudio propuesto se utilizó el análisis de los datos cuantitativos y cualitativos, visto que las relaciones entre las variables - gestión de la cadena de suministro y servicios, adoptada por las agencias de viajes, y su relación con los proveedores y clientes - fueron analizadas y cuantificadas para exponer comentarios y discutir tal situación entre los involucrados. La población objetivo de esta investigación estuvo integrado por todos los organismos afiliados a la Asociación Brasileña de Agencias de Viajes - ABAV seccional Santa Catarina. La muestra de identificación de la población se considera intencional, con la participación de 60 agencias de viajes y turismo que trabajan en el turismo emisivo y receptivo, características de servicio obligatorias para esta búsqueda. Se utilizó la técnica multivariante denominada análisis de agrupamientos, clasificación o cluster, organizada para comprender la situación de las agencias y entender la complejidad de las relaciones que coexisten entre las agencias de viajes y turismo y los participantes de la cadena. Los resultados son: las relaciones entre los agentes de viajes, sus clientes y proveedores, son superficiales, restringiéndose apenas a los aspectos comerciales de la transacción, comprometiendo una relación más personalizada y que contribuiría para la finalización del modelo de gestión tradicional, impuesta por los proveedores actuales.

Palabras clave: Gestión de la Cadena de Suministro y Servicios; Agencias de Viajes; Clientes y Proveedores; relacionamiento. 


\section{Introdução}

Viajar, conhecer novas culturas, diferentes atrativos e explorar lugares nunca visitados, é uma vocação que acompanha o homem ao longo da história. Essa necessidade de deslocamento gera atores que intermediam a vontade do viajante de estar em algum lugar e o fato de ele permanecer nesse lugar por determinado tempo.

O desejo de consumir o produto turístico cria um elo entre a demanda e a oferta turística, transformando a ideia de viajar em um acontecimento real, que requer a utilização e a organização do processo produtivo e distributivo da gestão da cadeia de suprimentos e serviços para a efetivação da atividade turística (NOVAES, 2001).

Toda essa "combinação" entre os elementos que compõem uma viagem - transportes, hospedagens, destinos, lazer, entretenimento e turista -, são funções atribuídas às agências de viagens, conhecidas tradicionalmente como agências de turismo (ANDRADE, 2000).

O fenômeno turístico nas agências é caracterizado pela relação entre uma série de elementos que se complementam e possibilitam que o turista, sujeito de todo o processo, alcance seu principal objetivo: realizar uma viagem. A falta de algum elemento que compõe a cadeia produtiva do turismo pode inviabilizar a realização de uma viagem para um determinado destino, seja ele turístico ou não. Um fator essencial na comercialização de produtos turísticos reside no fato de que este seja acessível para a visitação. Se a região escolhida por um viajante não é atendida por algum meio de transporte (aéreo, terrestre, marítimo ou lacustre), a impossibilidade de lá chegar, inviabiliza o atrativo como produto turístico (MILONE, 2000).

Nesse contexto, o "cliente" é o agente reconhecido como indispensável no planejamento das ações estratégicas das organizações que atuam no setor do turismo. Um fato que aponta ser imperativo, reside no investimento em pesquisas que caracterizem um produto como atrativo, que gerará o interesse das pessoas em visita-lo. Para que isso ocorra, o gerenciamento da cadeia de suprimentos e serviços desempenha um papel fundamental, pois possibilita que as organizações planejem as suas ações e as suas estratégias para a manutenção e a fidelização de seus clientes (RUSCHMANN, 2001; NAISBITT, 2011).

Para melhor compreender a situação das agências de viagem, é fundamental conhecer a sua realidade atual e o fenômeno turístico que conduz as suas relações com o mercado. 
Esta investigação aborda, de maneira sistemática, a atuação das agências de viagens no mercado do turismo e a importância do gerenciamento da cadeia de suprimentos e serviços como forças competitivas na gestão dessas organizações. $\mathrm{O}$ foco e a delimitação do problema se situam no agenciamento, o elemento que se posiciona no centro do sistema de turismo e na própria cadeia de suprimentos e serviços. A população alvo da pesquisa foi composta por todas as agências filiadas à Associação Brasileira de Agências de Viagens - ABAV, seccional de Santa Catarina. A amostragem de identificação da população considerada foi intencional, envolvendo as 60 Agências de Viagens e Turismo que atuam no turismo emissivo e receptivo, características de prestação de serviços necessárias para a significância do estudo.

Conceitualmente, considera-se que as agências de viagens estão ligadas diretamente as operadoras de turismo, hotéis, restaurantes, locais de entretenimento e outros equipamentos e que fornecem o composto desses serviços ou um deles ao turista, além de estarem ligadas a serviços complementares, avaliados a partir da sua interferência na Cadeia de Suprimentos.

Assim sendo, o principal objetivo deste estudo consistiu em avaliar o gerenciamento da cadeia de suprimentos nas agências de viagens e turismo no estado de Santa Catarina com enfoque no relacionamento das agências com seus fornecedores e clientes. Adotou-se a abordagem indutiva, ao buscar na realidade do sistema turístico, o comportamento do subsistema de agenciamento, no que se refere às suas estratégias competitivas, ações e tecnologias de distribuição do produto turístico, como elemento de compreensão da cadeia de suprimentos e de serviços. Desse modo, a investigação busca prover dados que auxiliem na compreensão, por parte dos agentes de viagens catarinenses, relacionada à gestão da cadeia de suprimentos, assim como na tomada de decisões, para a adoção das peculiaridades das suas relações entre clientes e fornecedores.

O fenômeno turístico faz parte da área social e as pesquisas desenvolvidas fundamentam-se no conhecimento empírico, fato este que estimulou a adoção do método científico da pesquisa social. Isso permitiu o levantamento, a observação e o experimento, fornecendo novos conhecimentos sobre opiniões, atitudes, hábitos e percepções dos empreendedores entrevistados - agentes de viagens, sobre os seus fornecedores e clientes. Estes se constituem nos componentes do processo da gestão da cadeia de suprimentos e serviços no subsistema de agenciamento de viagens em Santa Catarina (CAMPOMAR; KHAUAJA, 2007). 
Uma das teorias metodológicas utilizadas para entender esse processo foi a dos sistemas, elaborada por Beni (2001), que desenvolveu a Sistema de Turismo, o SISTUR. O principal propósito dessa teoria é racionalizar e simplificar a complexidade do mundo real do turismo e das viagens, em uma série de constructos e componentes que destacam a natureza interrelacionada do turismo. Sendo os estudos do turismo interdisciplinares, uma abordagem de sistemas pode abranger uma série de perspectivas diferenciadas, pois não supõe uma visão predeterminada do assunto.

O estudo também utilizou a análise de dados quantitativos e qualitativos, uma vez que as relações entre as variáveis - gestão da cadeia de suprimentos e serviços, adotada pelas agências de viagens, e sua relação com os fornecedores e clientes -, foram analisadas e quantificadas de forma a traçar comentários e discutir tal situação entre os envolvidos.

O trabalho assumiu características quanti-qualitativas, devido ao instrumento utilizado para coleta de dados - "questionário semiestruturado com perguntas abertas e fechadas". As características de uma análise quantitativa são utilizadas para descrever fatos das relações dos agentes de viagens com seus fornecedores e clientes, que geralmente são analisados por pesquisas qualitativas. Também é relevante dizer que as pesquisas têm sido caracterizadas pelo tipo de dados coletados e pela análise que se fará desses dados (CHIZZOTTI, 2006). Em função desta diferença muito tênue entre os tipos de pesquisas, a análise dos dados do presente trabalho ora se desenvolve de forma quantitativa, ora de forma qualitativa. (CHIZZOTTI, 2006).

A análise de agrupamentos apresentou a formação hierárquica dos indivíduos, levando em conta três conjuntos de variáveis: aquelas que avaliam o relacionamento das agências com os clientes, os fornecedores e a cadeia de suprimentos. Os agrupamentos foram gerados através do método de ligação completa (complete linkage), em que a similaridade entre dois conglomerados é definida pelos elementos que são "menos semelhantes" entre si, utilizando city-block (Manhattan), medida de distância, menos afetada pela presença de valores discrepantes na amostra das variáveis (MINGOTI, 2005).

Foi utilizado o software estatístico Sphinx para a tabulação e análise dos dados. O teste

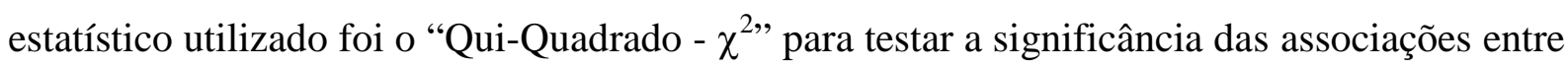
as variáveis. Para as demais análises, quando não empregado o $\chi^{2}$, foi utilizado o software Microsoft Excel, que permite realizar a análise dos dados individuais e cruzados, com o 
auxílio da ferramenta "filtro" do próprio programa, possibilitando comparações seguras entre variáveis e grupos de agências.

Ainda utilizou-se da técnica multivariada, análise de agrupamentos, também conhecida como análise de conglomerados ou cluster. Essa análise é caracterizada como um conjunto de técnicas estatísticas que tem como objetivo dividir os elementos da amostra, ou população, em grupos de forma que os elementos pertencentes a um mesmo grupo sejam similares entre si com respeito às variáveis (características) que neles foram medidas e para a formação dos grupos heterogêneos. (MALHOTRA, 2001; MINGOTI, 2005).

Constatou-se que poucas são as publicações que abordam a gestão da cadeia de suprimentos e serviços tendo como objeto de estudo as empresas de agenciamento de viagens e turismo. Portanto, os resultados desta pesquisa proporcionaram uma familiaridade maior com o tema, com vistas a torná-lo mais explícito. Além de identificar as características das agências de viagens que compuseram a amostra, no que diz respeito à importância que atribuem à gestão da cadeia de suprimentos e serviços, a fim de proporcionar uma nova visão do problema.

\section{As Agências de Viagens, Conceitos e Funções}

As empresas chamadas agências de viagens enquadram-se no setor terciário da economia, ou seja, são responsáveis pela produção e intermediação de serviços de agenciamento de viagens. Suas relações com os demais elementos que compõem a atividade turística são de intensa interdependência, pois nenhuma viagem de turismo ocorre com seus componentes de forma isolada (BENI, 2003; TOMELIN e TEIXEIRA, 2005; PELIZZER, 2006)

Para cumprir com seus objetivos, as agências de viagens dependem de uma série de elementos da cadeia de distribuição em que cada prestador de serviços, pode vender diretamente aos consumidores finais ou por meio de intermediários, entre eles as agências de viagens (ACERENZA, 1990).

As agências assumem a função de organizadoras e executoras de programas de viagens quando "fabricam" produtos turísticos, a partir da combinação de diferentes insumos disponíveis no mercado, tais como: serviços de transportes, alojamento, entretenimento, etc.; 
situação esta, para a qual Beni (2001) lembra que: "Organização de viagens: deve estar de acordo com o desejo do cliente, seja individualmente ou em grupo".

No processo comercial entre a agência de viagens e o consumidor, concretiza-se a função de relacionamento e serviços. Esse é o processo que disponibiliza os produtos turísticos aos consumidores finais, ligando o fornecedor ao consumidor. Nessa relação, tradicionalmente, as agências de viagens recebem uma comissão dos fornecedores pelos produtos comercializados. Para Cooper et al. (2001) o agente de viagens tem a função de intermediação e aceita que novas correntes atribuam o papel de consultor à figura do agente. Porém, cabe às agências atacadistas e aos fornecedores o papel do desenvolvimento e a operação de "pacotes de viagens", bem como a promoção dos destinos e dos produtos turísticos.

A função de promotora é assumida quando a agência divulga os destinos turísticos, dinamizando a atividade em todo o mundo. Essa é uma importante função da agência, visto que, em muitos destinos turísticos, as agências de viagens são responsáveis por uma parcela significativa dos turistas (MARÍN, 2004; TOMELIN e TEIXEIRA, 2005).

Tomelin (2001) ressalta que os agentes denominados provedores são as transportadoras aéreas e rodoviárias, a indústria hoteleira e demais provedores/fornecedores de produtos e serviços receptivos, os quais se constituem em componentes da indústria de viagens, tradicionalmente ligados às agências de viagens e turismo e, promocionalmente, ao fomento de destinos turísticos.

A função de assessora é prestada aos clientes sempre que estes necessitam de informações, sugestões e orientações a respeito dos mais diversos produtos e destinos comercializados e promovidos em uma agência de viagens.

Nesse sentido, observa-se que, no Brasil, as agências de viagens "trabalham" para os fornecedores em razão dos comissionamentos, pois são estes que lhes garantem as receitas financeiras, diferentemente do que apontam as tendências mundiais no sentido de que as agências passarão a assumir o papel de assessoras de viagens, recebendo taxas de serviços, pagos pelo cliente (turista), pelos serviços prestados. 


\section{Cadeia de Suprimentos, Serviços e Relacionamento}

A concepção logística de agrupar as atividades relacionadas ao fluxo de produtos e serviços para administrá-las de forma coletiva, é uma evolução natural do pensamento administrativo. As atividades de transportes, estoques e comunicações iniciaram-se antes mesmo da existência de um comércio ativo. Hoje, as empresas devem realizar essas mesmas atividades como uma parte essencial de seus negócios, a fim de prover seus clientes com os bens e serviços que eles desejam (BALLOU, 1993; CHRISTOPHER, 2004).

Para um melhor entendimento do estudo, é importante conhecer os diferentes conceitos que constitui esta base teórica:

A origem do conceito de cadeia de suprimentos e serviços ou abastecimento tem sido inspirada por muitas áreas, incluindo (1) a revolução da qualidade (DALE et al., 1994.), (2) noções de materiais gestão e logística integrada (CARTER E PRICE, 1993; FORRESTER, 1961), (3) um interesse crescente nos mercados industriais e redes (FORD, 1990; JARILLO, 1993), (4) aumento da noção de foco (PORTER, 1987;. SNOW et al., 1992), e (5) estudos específicos da indústria influente (WOMACK et al, 1990; LAMMING, 1993). Assim, pesquisadores encontraram-se inundados com terminologias, como "cadeias de fornecimento", "dutos de demanda" (FARMER e VAN AMSTEL, 1991), "fluxos de valor" (WOMACK E JONES, 1994), "redes de apoio", e muitas outras. A gestão da cadeia de suprimentos (SCM) foi originalmente introduzida por consultores no início de 1980 (OLIVER E WEBBER, 1992) e posteriormente ganhou enorme atenção (LA LONDE, 1998). Analiticamente, uma cadeia de fornecimento típica conforme mostrado na Fig. 1 é uma rede de materiais, informações e serviços de ligações com as características da oferta, transformação e demanda de processamento.

O termo SCM tem sido usado para explicar o planejamento e controle de materiais e fluxos de informação, bem como as atividades de logística, não só internamente dentro de uma empresa, mas também externamente entre companhias (COOPER et al , 1997; FISHER, 1997). 


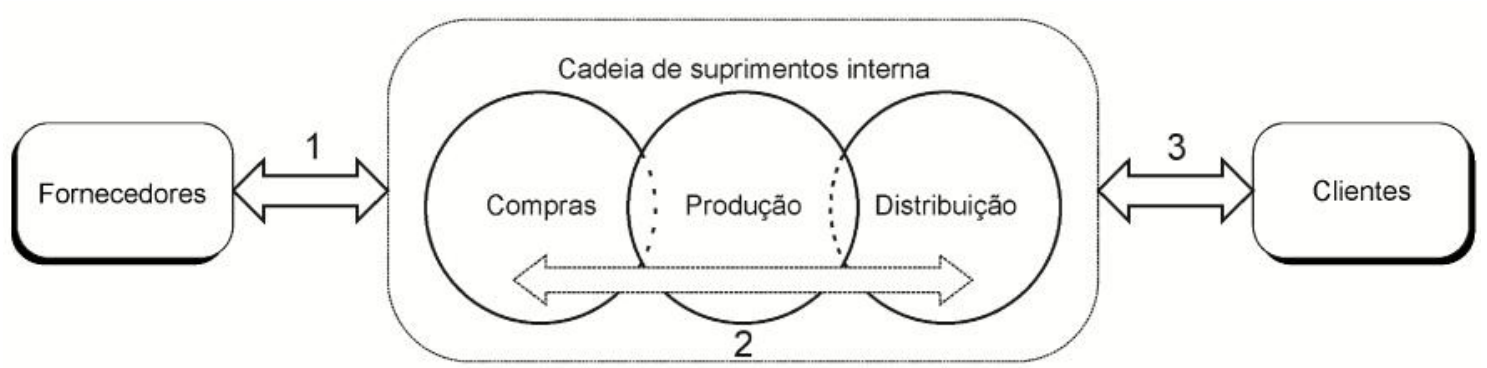

Figura 1 - Uma ilustração da cadeia de suprimentos da empresa.

Fonte: Chen e Paulraj, 2003.

Pesquisadores também usaram para descrever, questões inter-organizacionais estratégicas (HARLAND et al, 1999), para discutir uma forma de organização alternativa à integração vertical (THORELLI, 1986; HAKANSSON e SNEHOTA, 1995), para identificar e descrever a relação que a companhia desenvolve com seus fornecedores (HELPER , 1991; Hines , 1994; NARUS e ANDERSON, 1995), e para tratar de compra e perspectiva da oferta (MORGAN e MONCZKA, 1996; FARMER, 1997).

Certo número de domínios, tais como compras e suprimentos, logística e transporte, gestão de operações, marketing, teoria organizacional, a Informação de gestão, e gestão estratégica tem contribuido para a explosão da literatura SCM.

O gerenciamento logístico engloba, assim, o conceito de fluxo de compras de matéria prima, operações de produção e de transformação, controle de materiais e processos, bem como produtos acabados, compreendendo, também, todo o gerenciamento de transporte $\mathrm{e}$ distribuição de produtos destinados a vendas, até os consumidores finais (ARNOLD, 1999)

No turismo, a distribuição dá-se antes da produção, com a venda dos serviços, a exemplo do resort, que precisa ser oferecido ao cliente, podendo ser através de uma venda direta ou indireta pelas agências de viagem e turismo.

A compreensão do nível de serviço é a qualidade com que o fluxo de bens e serviços é gerenciado, tornando-se fator-chave no conjunto de valores logísticos que as empresas oferecem a seus clientes com o intuito de assegurar sua fidelidade (PORTER, 1985; CHRISTOPHER, 2004). 
Segundo Novaes (2001), para chegar-se ao estágio de integração plena, com benefícios globais expressivos, é necessária a eliminação de inúmeras barreiras. Uma delas é o esquema organizacional da empresa, que precisa ser modernizado.

Outro requisito é a necessidade de um sistema de informações bem montado e interligado com todos os parceiros da cadeia. Também é preciso implantar, nas empresas participantes, sistemas de custos adequados aos objetivos pretendidos, permitindo a transparência de informações entre os parceiros da cadeia. Esse tipo de operação logística integrada e moderna é denominado de Supply Chain Management (SCM), ou, em português, Gerenciamento da Cadeia de Suprimentos. A definição, adotada pelo Fórum de SCM realizado na Ohio State University, trata de atos que integram os processos industriais e comerciais, partindo do consumidor final e indo até os fornecedores iniciais, gerando produtos, serviços e informações que agreguem valor para o cliente (MARIEN, 1998).

Essa definição do SCM é bastante aceita, pois sua caracterização geralmente envolve muito mais a ideia de parceria e de relacionamento coorporativo do que da administração usual. Sua concepção declara uma relação win-win (ganha-ganha) cujos fornecedores e clientes ganham com o melhor atendimento ao consumidor final e com toda a cadeia de atividades necessárias para agregar valores ao consumidor final. Essa integração administrativa tem por objetivo fazer com que os produtos da cadeia sejam mais competitivos, de baixo custo, de alta qualidade, mais confiáveis, mais diversificados e de pronta entrega.

As estratégias de logística e a cadeia de suprimentos surgem da relação com os fornecedores e alguns benefícios resultam dessa integração, que Ching (1999) relaciona como sendo:

1. Parceiros mais fortes e para todo o negócio.

2. Foco comum na qualidade.

3. Confiabilidade de entregas mais estáveis e repetitivas.

4. Baixos níveis de estoques.

5. Menos burocracia.

6. Melhor controle do processo.

7. Dependência mútua e congruência de objetivos.

8. Custos da cadeia logística reduzida.

Assim, a parceria pode ser definida como um relacionamento comercial sob medida, com base em confiança mútua, abertura, riscos e recompensas compartilhados, que proporciona 
vantagem competitiva estratégica, resultando em um desempenho melhor do que seria possível individualmente.

$\mathrm{Na}$ cadeia, promover parcerias com fornecedores é vital. Permite ganho de eficiência operacional, que não seria possível de outra maneira, levando a vantagens de integração vertical e de melhor especialização do ramo e constitui-se em uma forma de reagir à concorrência, assegurando ou fortalecendo posições.

A otimização da parceria entre a empresa e seus fornecedores gera uma cadeia de valor que é toda atividade estratégica que proporciona valores ao cliente. O valor é o que o cliente está disposto a pagar ou que ele perceba que está incluído no produto ou serviço, gerando receita para a empresa. "A cadeia de valor desdobra a empresa em suas atividades estrategicamente relevantes, para compreender o comportamento dos custos e as fontes de diferenciação existentes ou potenciais". (PORTER, 1985, p. 31).

Essas atividades de valor são: logística interna, operações, logística externa, marketing, vendas e serviços, que, na cadeia de valor, têm suas atividades de apoio na infraestrutura da empresa, na gerência de recursos humanos e no desenvolvimento de tecnologia. A empresa alcança vantagem competitiva executando suas atividades de valor estratégico de maneira mais barata.

Percebe-se que a cadeia de valor está presente desde a entrada da matéria prima até a utilização do produto ou serviço pelo cliente e sua gestão eficaz pode garantir vantagens diferenciadas à empresa. Segundo Christopher (2004), a gestão da cadeia de suprimento visa tornar as redes mais eficientes na satisfação das exigências do usuário final. Isso requer um alto nível de cooperação entre as organizações participantes e o reconhecimento da necessidade de tornar os relacionamentos das empresas mutuamente benéficos. Essa cadeia caracteriza-se pelo enfoque em:

- Um prévio envolvimento dos fornecedores no processo de desenvolvimento de novos produtos;

- Um programa conjunto de melhoria contínua de produtos e de processos facilitados pela transparência dos custos em ambas as direções;

- Um acordo sobre objetivos de desempenho e de critérios de avaliação.

Uma cadeia de suprimentos típica do setor de turismo é apresentada na Figura 2 a seguir. Fornecedores de matéria-prima entregam insumos de natureza variada para a indústria principal (Hotelaria) e também para operadores de turismo que participam da montagem, 
confecção e promoção do produto, aqui baseadas no SISTUR de Beni (2001). A indústria de hotéis comercializa o produto em questão diretamente ao consumidor, ou por meio das agências de viagens e, em parte, diretamente aos distribuidores informais do mercado. Esses distribuidores fazem o papel de intermediários, pois, na maioria das vezes, as agências não comercializam um volume suficiente do produto que possibilite a compra direta dos "pacotes turísticos" ofertados pelas destinações turísticas. Já as operadoras comercializam indiretamente o produto ao consumidor final por meio das agências e distribuidores. Há, ainda, outros aspectos não considerados na Figura 2, como a Logística Reversa e as operações de pós-venda.

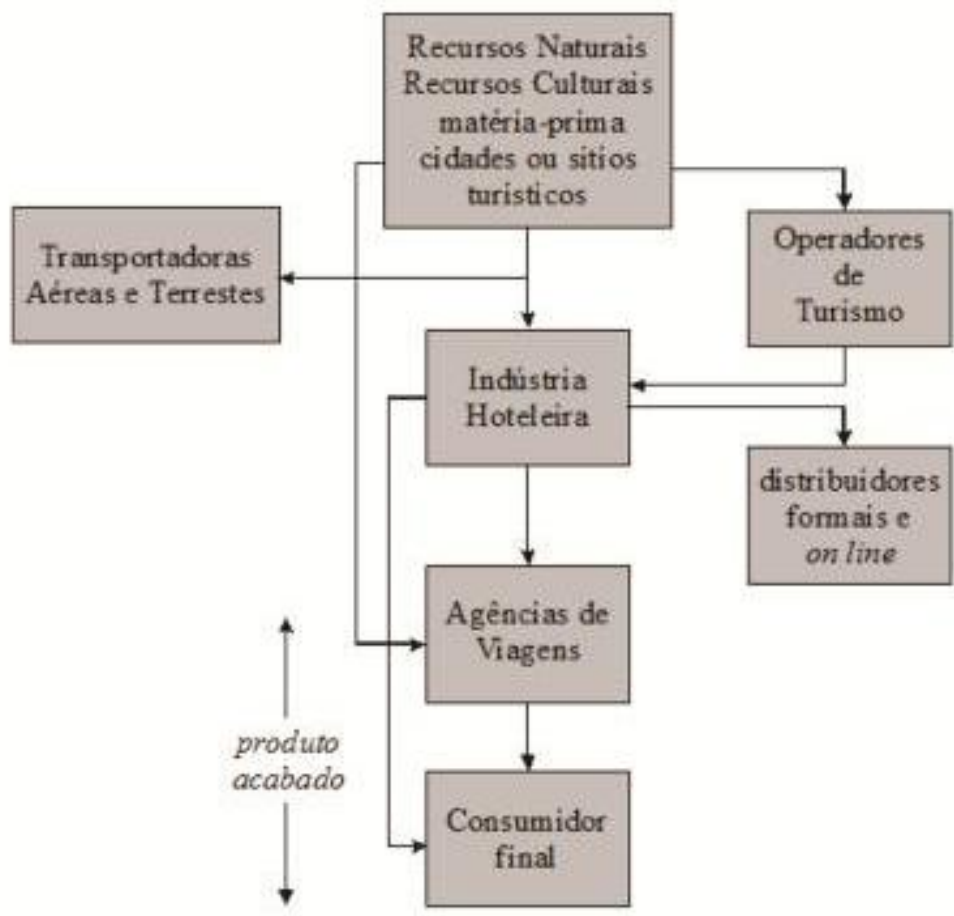

Figura 2 - Cadeia de Suprimentos

Fonte: Adaptada por Tomelin com base em Novaes (2001).

Por definição, a estrutura e a organização das agências de viagens estão ligadas às funções básicas de promoção, de reservas e de vendas de serviços de transportes, alojamento, alimentação, visita a lugares e a eventos de interesse, transporte local e visitas organizadas, além da facilitação do trâmite de documentos como passaporte, vistos, seguros, vacinas, etc. (TORRE, 1990). Nota-se a importância da relação entre a agência com os efetivos prestadores 
de serviços de transporte, alojamento e facilidades que perfazem a organização de uma viagem, enquadradas no subsistema do turismo - o agenciamento.

Dependendo da tipologia e da atuação da Agência de Viagens e Turismo no mercado de viagens em que está inserido, a empresa terá de definir, adequadamente, a sua estrutura, tipo e matriz de serviços, consequente organização estrutural e funcionamento integrado com os provedores de serviços turísticos, a exemplo do demonstrado na Figura 2.

A importância do Gerenciamento da Cadeia de Suprimentos demonstra como a organização posiciona-se em suas competências para obter vantagem competitiva. Logo, SCM inclui o projeto e a administração de sistemas para controlar o fluxo de materiais, materiais em processo, estoque de produtos acabados e consumidores, para suportar a estratégia da unidade de negócio.

\section{Análise e Discussão dos Resultados}

A análise se inicia com um diagnóstico e caracterização das agências entrevistadas, identificando-as e fazendo breves referências em relação às atividades desenvolvidas, serviços prestados e produtos por elas comercializados e prossegue com a análise da relação das agências com seus clientes e fornecedores e com a gestão da Cadeia de Suprimentos, Serviços e Relacionamento.

Os principais focos da pesquisa referem-se à Gestão da Cadeia de Suprimentos e Serviços na relação entre fornecedores e a prestação de serviços do Agente de Viagens no Estado de Santa Catarina.

Foram pesquisadas intencionalmente as Agências de Viagens e Turismo filiadas à ABAV/SC, através da devolução do instrumento de pesquisa - Medida de Identificação e de Atitude, resultando em $63 \%$ de participação por amostragem acidental (GIL, 2002).

A geração, definição e análise dos grupos levou em conta as variáveis: tipologias, características de serviços, porte e tempo de atuação no mercado.

A Figura 3 apresenta os indivíduos agrupados por meio do Dendograma. Na base estão as 39 agências (inicialmente cada agência representa um cluster). $O$ processo de agrupamento vai unindo as agências que mais se assemelham, à medida que o número de agrupamentos 
diminui aumenta a variabilidade dentro do grupo (no limite todas as agências formam um só grupo). Um dos critérios para parar o processo de agrupamento e definir o número de grupos pode ser a ocorrência de saltos muito grandes nos valores das distâncias (MALHOTRA, 2001; MINGOTI, 2005).

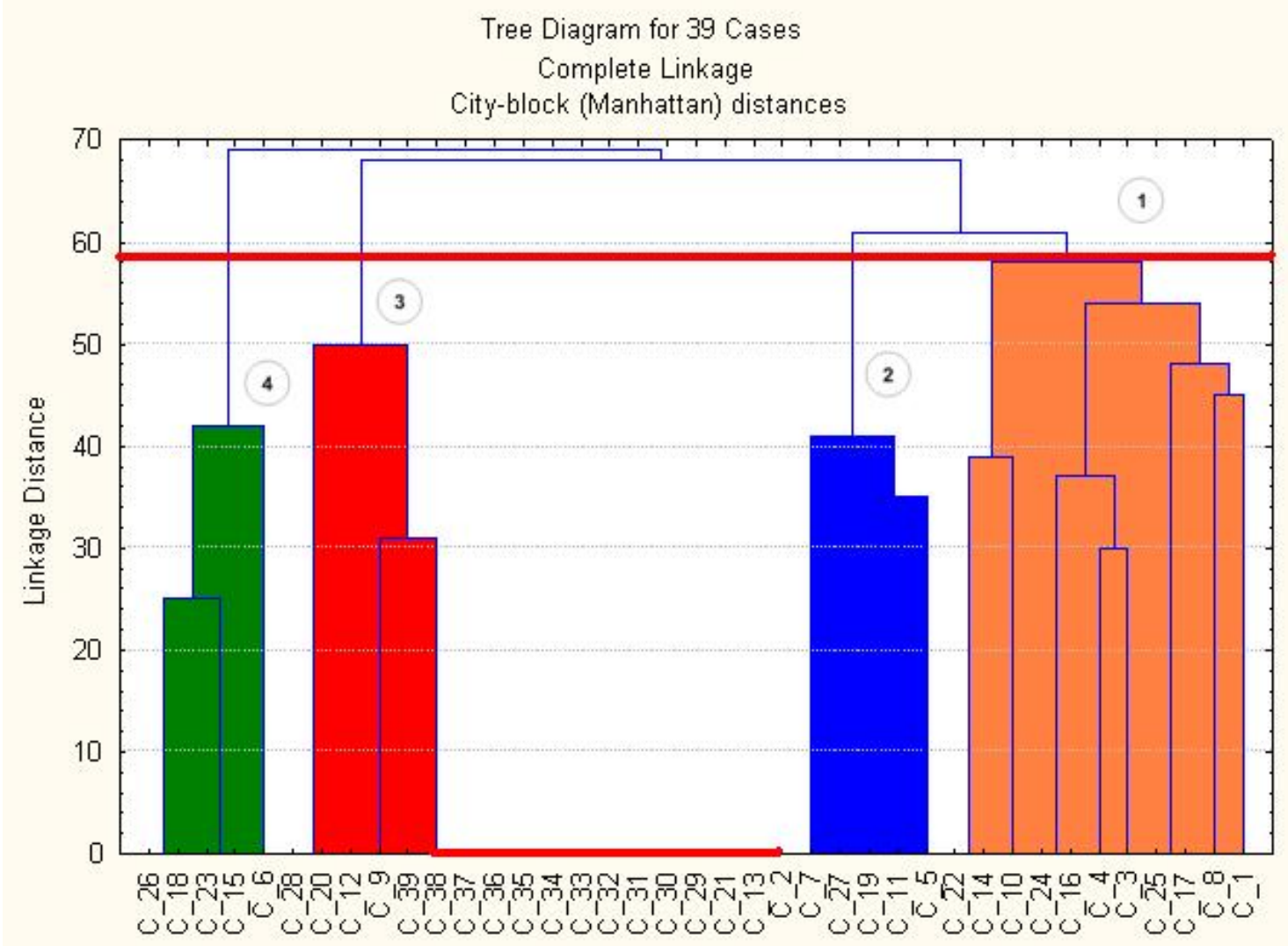

Figura 3 - Dendograma dos agrupamentos, passo a passo, utilizando o método de ligação completa (Complete Linkage) e medida de distancia city block (Manhatan)

Fonte: Autores, 2013.

Analisando visualmente a Figura 3, pode-se observar que a interrupção no processo de agrupamentos foi feita no ponto em que a medida de distância gira em torno de 58 , o que resultou na formação de 4 clusters assim compostos:

Grupo 01, composto pelas agências: 1, 3, 4, 8, 10, 14, 16, 17, 22, 24 e 25 do banco de dados, apresentam características de similaridade responsável pela sua formação no que tange a tipologia, neste grupo as agências são formadas na sua quase totalidade por agências de viagens do tipo Detalhista que para Acerenza (1996), Pellizzer e Scrivano (2005). E por 
apenas uma agência de viagens do tipo Maioristas, que para Piñole (2000); Acerenza (1996); Pelizzer (2006), têm como principal objetivo a confecção de programas de viagens organizados, vendendo, em alguns casos, o produto diretamente ao consumidor final, por essas características de serviços serem muito similares, certamente os $11 \%$ de agências maioristas (1 agência) que estão no grupo deve-se à variável de proximidade de serviços oferecidos, compondo esse grupo. Nesta mesma caracterização por similaridade, que aproxima este grupo, está a questão comercial do ponto de venda, que se caracterizam por empresas, matrizes não pertencendo a nenhum grupo empresarial, ou franquias e não possuem filiais.

Outra característica de similaridade encontrada é o tempo de atuação no mercado, em média atuam há cerca de 6 anos e se constituem na sua totalidade por agências de pequeno e médio porte, (ABAV, 2010). Quanto ao nível de formação dos dirigentes esse grupo se caracteriza por sua totalidade de empresários com nível superior, sendo que somente dois possuem formação em Turismo, e os demais são formados em outras áreas do conhecimento, (Administração, Geografia, Economia e Direito).

Grupo 02, composto pelas agências: 5, 7, 11, 19 e 27 do banco de dados, apresentam características de similaridade responsável pela sua formação no que tange a tipologia, neste grupo as agências são formadas na sua totalidade por agências de viagens do tipo Detalhistas, Acerenza (1996), Pellizzer e Scrivano (2005), além desta característica, esse grupo é formado também por empresas, matrizes que não pertencem a nenhum grupo empresarial, ou franquias e não possuem filiais, essas empresas atuam no mercado, em média há de 10 anos e se constituem na sua totalidade por agências de pequeno porte (1 a 3 funcionários) e médio porte (4 a 9 funcionários), (ABAV, 2010).

Quanto ao nível de formação dos dirigentes esse grupo se caracteriza por sua totalidade de empresários com nível superior formados em outras áreas do conhecimento, (Administração, Geografia, Economia e Direito) sendo que dois desses possuem mestrado em Turismo e Hotelaria.

A característica mais marcante que distingue esse grupo dos demais esta na formação do agrupamento, pois neste grupo encontramos na sua totalidade agências de viagens do tipo Detalhistas essa homogeneidade foi verificada em todos às vezes em que se programou a análise de agrupamento, com diferentes variáveis, essas agências sempre estiveram juntas 
Essa homogeneidade, encontrada no grupo 2 apesar de ser um item que o distingui dos demais, também representa que as agências de viagens catarinense possuem características muito semelhantes quando comparadas pela prestação de serviços em relação a sua tipologia, tempo de atuação no mercado e porte.

Grupo 03, composto pelas agências: 2, 9, 12, 13, 20, 21, 28, 29, 30, 31, 32, 33, 34, 35, 36, 37, 38 e 39 do banco de dados, apresentam características de similaridade responsável pela sua formação no que tange a tipologia, neste grupo as agências são formadas na sua totalidade por agências de viagens do tipo - Maioristas e do tipo - Operadoras de Turismo que para Piñole,(2000), Acerenza (1996), Pellizzer (2006), as agências de viagens maioristas e operadoras de turismo se confundem, empregando as mesmas funções operacionais tanto para as agências maioristas quanto para as operadoras. O termo para designar essas empresas é “operadora", por tanto esse grupo é bastante homogêneo em seu processo de formação.

Quanto ao nível de formação dos dirigentes esse grupo se caracteriza por sua totalidade de empresários com nível médio técnico.

Outra característica de formação que distingue as agências que compõem esse grupo esta no tempo de atuação no mercado destaca se uma experiência de mais de 10 anos, dado que pode levar há uma análise de que as empresas que possuem um maior grau de complexidade em suas atividades ou tipologia são as agências com maior experiência e estão a mais tempo no mercado.

Grupo 04, composto pelas agências: 6, 15, 18, 23 e 26 do banco de dados, apresentam características de similaridade responsável pela sua formação no que tange a tipologia, neste grupo as agências são formadas na sua quase totalidade por agências de viagens do tipo Detalhistas e do tipo - Maioristas, apesar de haver registro dessas agências nesse grupo, (uma agência) deve-se a outra variável que as aproxima na formação e são similares as demais quando comparadas com a estrutura comercial, são empresas, matrizes não pertencendo a nenhum grupo empresarial, ou franquias e não possuem filiais. Essas empresas se constituem na sua totalidade por agências de médio porte (4 a 9 funcionários), e grande porte (mais de 10 funcionários), ABAV (2010). Desse modo as características de formação são essencialmente de agências do tipo - Detalhistas.

Outra característica de formação que distingui as agências que compõem esse grupo está no tempo de atuação no mercado, destacando-se uma experiência em média de 10 anos. 
Quanto ao nível de formação dos dirigentes esse grupo se caracteriza por sua totalidade de empresários com nível superior, formados em outras áreas do conhecimento, (Administração, Geografia, Economia e Direito).

A característica mais marcante deste grupo que o distingue dos demais está no porte das agências entrevistadas, formadas por médias e grandes empresas. A formação do grupo 4, comparado à realidade nacional das agências pesquisadas pela ABAV (2010), são compatíveis pelo tipo de serviços e produtos comercializados.

Após a caracterização dos 4 grupos, verificamos que as distinções entre um grupo e outro estão relacionadas as variabilidades de composição ou junção de cada grupo, isso também pode acontecer em função das similaridades existentes entre as agências entrevistadas no momento de sua formação.

As variáveis de relacionamento na Cadeia de Suprimentos e Serviços atendem os objetivos de estudo, analisando os principais fatores que proporcionam a parceria nas relações entre agências de viagens e turismo, fornecedores e clientes, utilizando os conceitos da Cadeia de Suprimentos e Serviço como estratégia de gestão, e a realidade e visão catarinense sobre a Gestão da Cadeia de Suprimentos e Serviço no setor de viagens.

\subsection{A gestão da cadeia de suprimentos e serviços na visão do agente de viagens catarinense.}

A gestão cadeia de suprimentos e serviço na visão do agente de viagens catarinense é identificada na política de organização para o gerenciamento da cadeia de suprimento e serviços. A expressão cadeia de suprimento é uma metáfora usada para descrever as empresas que estão envolvidas no fornecimento de um produto ou serviço (GIANNAKIS, 2001).

A Tabela 1, apresenta a forma de como as agências estão organizadas para gerenciar os relacionamentos com a SCM, verificou-se que nenhuma das agências entrevistadas se organiza por meio da consultoria externa, suas ações para a gestão dos relacionamentos na cadeia de suprimentos, depende da força de trabalho implementada na própria equipe de colaboradores ou dos dirigentes.

Como se pode observar grande parte das agências - geralmente as detalhistas ou maioristas formadas pelos grupos $\mathrm{G} 2$, ( $80 \%$ ) e G3 ( mais de $77 \%$ ), preferem que a própria equipe formada por um colaborador do setor desenvolva de forma direta a organização para o 
gerenciamento das relações com os clientes e fornecedores. Já para os grupos G1(60\%) e G4 (100\%), preferem a equipe formada pelos dirigentes, nesta análise verificamos que o grupo 4 se destaca dos demais em razão da totalidade de respostas, isso pode levar a compreensão que os processos decisórios desse grupo estão concentrados nos dirigentes. Neste sentido para a teoria da gestão da cadeia de suprimentos pode causar dificuldades nos fluxos e processos de relacionamentos entre os clientes e fornecedores. (PORTER, 1985; CHRISTOPHER, 2004).

A cadeia de suprimentos e serviços deve trabalhar com o desenvolvimento de relações colaborativas entre os diversos elos dessa rede, em todos os processos logísticos e por todos os participantes da cadeia desde o fornecedor até o cliente final, evitando dessa forma a concentração e a verticalização das informações em determinados elos da cadeia. (CHEN; PAULRAJ, 2003).

Tabela 1 - Como a agência está organizada para gerenciar os relacionamentos com a Cadeia de Suprimentos.

\begin{tabular}{l|c|c|c|c|c}
$\begin{array}{l}\text { Organização da agência para o } \\
\text { Gerenciamento da Cadeia de } \\
\text { Suprimentos }\end{array}$ & $\mathbf{1}$ & $\mathbf{2}$ & $\mathbf{3}$ & $\mathbf{4}$ & \multirow{2}{*}{ TOTAL } \\
\hline $\begin{array}{l}\text { De forma direta por um colaborador do } \\
\text { setor/área }\end{array}$ & 20,00 & 80,00 & 77,78 & 0,00 & 52,63 \\
\hline $\begin{array}{l}\text { Equipe de colaboradores de vários } \\
\text { setores/área }\end{array}$ & 20,00 & 0,00 & 16,67 & 0,00 & 13,16 \\
\hline $\begin{array}{l}\text { Equipe formada pela gerência e/ou } \\
\text { diretoria }\end{array}$ & 60,00 & 20,00 & 5,56 & 100,00 & 34,21 \\
\hline Consultoria externa & 0,00 & 0,00 & 0,00 & 0,00 & 0,00 \\
\hline TOTAL & $\mathbf{1 0 0 , 0 0}$ & $\mathbf{1 0 0 , 0 0}$ & $\mathbf{1 0 0 , 0 0}$ & $\mathbf{1 0 0 , 0 0}$ & $\mathbf{1 0 0 , 0 0}$ \\
\hline
\end{tabular}

Os valores da tabela são os percentuais em coluna estabelecidos sobre 38 citações. Fonte: Autores, 2013.

As ações que deverão ser implementadas para melhorar o relacionamento com a cadeia de suprimentos e serviços pelas empresas pesquisadas, identificadas na Tabela 2, apresentam uma boa percepção à respeito da aplicação do conceito de SCM. Segundo os dados obtidos, a maioria das agências que compõem os grupos G1, G2 e G3 que representa acima de 66\% das entrevistadas consideram a implantação ou a melhoria na gestão dos relacionamentos com os membros da cadeia (fornecedores, clientes e intermediários), muito importante.

O grupo 4, composto pelas agências de viagens do tipo - Detalhista concentram suas preferências nas mudanças gerenciais de suas empresas e na negociação com fornecedores, 
sendo que numa visão mais generalista parece que as agências que formam os 4 grupos tendem a implantar no futuro ações de gestão de relacionamentos entre os membros da cadeia de suprimentos e serviços.

Embora a estratégia atual adotada pelas empresas não se encontre em consonância com a teoria, a qual sinaliza que, na sociedade do conhecimento, as empresas deveriam buscar relacionamentos de confiança em cadeia, já existe a percepção da importância da gestão dos relacionamentos, uma vez que as agências encontram-se compelidas a encaminhar no futuro para este estágio (CHEN; PAULRAJ, 2003).

Tabela 2 - Ações a serem implantadas na agência para que tenha um melhor relacionamento com a Cadeia de Suprimentos

\begin{tabular}{|c|c|c|c|c|c|}
\hline \multirow{2}{*}{$\begin{array}{l}\text { Ações que deverão ser implantadas na } \\
\text { agência para melhorar o } \\
\text { relacionamento com a Cadeia de } \\
\text { Suprimentos }\end{array}$} & \multicolumn{4}{|c|}{ CLUSTER } & \multirow[b]{2}{*}{ TOTAL } \\
\hline & 1 & 2 & 3 & 4 & \\
\hline Planejamento da Cadeia de Suprimentos & 0,00 & 0,00 & 0,00 & 0,00 & 0,00 \\
\hline Planejamento Estratégico & 0,00 & 20,00 & 0,00 & 0,00 & 2,78 \\
\hline Integração de sistemas & 0,00 & 0,00 & 0,00 & 0,00 & 0,00 \\
\hline Gerenciamento de Projetos & 0,00 & 0,00 & 0,00 & 0,00 & 0,00 \\
\hline Mudanças gerenciais & 0,00 & 0,00 & 0,00 & 40,00 & 5,56 \\
\hline Negociação com fornecedores e parceiros & 37,50 & 0,00 & 5,56 & 40,00 & 16,67 \\
\hline Gestão de operações & 25,00 & 0,00 & 0,00 & 20,00 & 8,33 \\
\hline Gestão de relacionamentos & 37,50 & 80,00 & 94,44 & 0,00 & 66,66 \\
\hline Planejamento de facilidades & 0,00 & 0,00 & 0,00 & 0,00 & 0,00 \\
\hline Outros & 0,00 & 0,00 & 0,00 & 0,00 & 0,00 \\
\hline TOTAL & 100,00 & 100,00 & 100,00 & 100,00 & 100,00 \\
\hline
\end{tabular}

Os valores da tabela são os percentuais em coluna estabelecidos sobre 36 citações.

Fonte: Autores, 2013.

A visão das agências de viagens catarinenses sobre a Cadeia de Suprimentos e Serviços, a partir da implantação ou melhoria no relacionamento com a cadeia e seus membros (fornecedores, clientes e intermediários), evidencia uma tendência de mudanças no cenário catarinense em relação às posturas de gestão dos relacionamentos. A quase totalidade entre os 4 grupos formados pelo Dendograma dos agrupamentos, Figura 3, ou seja, mais de $76 \%$ das agências que compõem os clusters consideram "muito importante", seguida de importante por mais de $20 \%$ das agências dos grupos. 
Essa tendência confirma a intenção destas agências para uma mudança de comportamento, vindo ao futuro desenvolver ações cooperativas com fornecedores e distribuidores, melhorando a cadeia produtiva e produzindo mais valor em conjunto. Com relação à estratégia futura de relacionamento com os fornecedores, sinaliza - se a intenção de se adotar uma estratégia mais sofisticada, no futuro pelas agências de viagens, independente da formação dos agrupamentos (MARÍN, 2004).

Para que haja um melhor relacionamento com a Cadeia de Suprimentos, é necessário, segundo as agências, que ações como planejamento estratégico, negociação com fornecedores e parceiros e a integração de sistemas sejam implantadas. Nenhuma agência entrevistada identificou como não sendo importante a implantação deste novo relacionamento.

\section{Considerações Finais}

Com o avanço da tecnologia, principalmente com o advento da Internet, os consumidores passaram a ter acesso fácil às informações e, assim, maior conhecimento em praticamente todas as atividades que o cercam. Considerando o objetivo geral do presente estudo, que é o de avaliar o Gerenciamento da Cadeia de Suprimentos nas agências de viagens e turismo no Estado de Santa Catarina com enfoque no relacionamento das agências com seus fornecedores e clientes, a pesquisa realizada conduziu à conclusão de que essa situação não é diferente nas agências de viagens, as quais, nos dias atuais, assistem ao rápido processo de mudanças que colocam o cliente final frente aos fornecedores, causando um encurtamento na cadeia distributiva, colocando em cheque sua função de intermediária de produtos e de serviços turísticos.

Atualmente, o grande crescimento na dinâmica das tecnologias gerenciais em vários segmentos empresariais, utilizadas de forma a informar e demonstrar os serviços oferecidos aos clientes de forma rápida e, muitas vezes, de forma interativa. Nesse sentido, a informação pode constituir-se em vantagem competitiva também nas organizações turísticas.

Dessa forma, verificou-se a importância e a compreensão de novas atribuições da distribuição do produto turístico no setor de viagens a partir do Gerenciamento da Cadeia de Suprimentos e Serviços nas Agências de Viagens. 
Verificou-se, também, que o novo modelo competitivo mudou do convencional "unidade individual de negócios" para "unidade coletiva de negócios", focada na cadeia de suprimentos. (MARÍN, 2004; CHEN e PAULRAJ, 2003).

Nesse sentido, o setor de viagens e turismo, independentemente da função e da tipologia vinculada, é caracterizado pelas atividades econômicas do setor, e de acordo com a pesquisa realizada, na fase de intermediação e distribuição dos produtos ao consumidor final. Este serviço é reconhecido dentro dos canais de distribuição como o mercado varejista, que é influenciado diretamente pelo Gerenciamento da Cadeia de Suprimentos e Serviços. A pesquisa realizada foi importante para identificar os conceitos que devem ser revistos para adequar o modelo industrial (SCM) ao setor de viagens. Esta revisão será fundamental para o futuro das Agências de Viagem e Turismo em razão da distinção entre os serviços e o processo de produção, uma vez que o a prestação dos serviços de turismo é caracterizada pela intangibilidade e a simultaneidade da produção e do consumo.

Os agentes de viagens, em sua maioria, trabalham em uma espécie de situação de concorrência coletiva por serem muito numerosos, oferecem serviços similares, possuindo, portanto, dificuldades em se diferenciar. Suas vantagens competitivas, basicamente, referemse ao relacionamento estabelecido com o consumidor que permite criar preferências e desenvolver a política de fidelização.

Para serem competitivas, sugere-se que as agências de viagens utilizem a tecnologia da informação para agregar valor aos serviços oferecidos ao cliente e criar diferenciais de modo a reduzir, significativamente, o poder competitivo dos seus concorrentes. Assim, a empresa precisa oferecer um produto de qualidade, integrando o maior número de informações a esse produto. A tecnologia da informação proporciona esse processo a qualquer tipo de organização, inclusive àquelas que dispõem de poucos recursos financeiros.

Frente às novas tecnologias e as vantagens que estas oferecem ao mercado de viagens e turismo, a capacitação profissional do setor torna-se imprescindível para o bom desempenho das funções. $\mathrm{O}$ acesso às fontes de informações do agente de viagem - além da tradicional e cara "folheteria" e material impresso, o acesso à rede mundial de computadores e os sistemas globais de distribuição (GDS) -, tornam o trabalho muito mais fácil, ágil, seguro e, o que é mais interessante, com um custo menor. 
A desvantagem apresentada é que o desenvolvimento das atividades do serviço no setor, dentro de cada fase da cadeia, torna-se lento quando não bem coordenado, pois se ocorrem atrasos na tomada de decisões pelos fornecedores, as agências, distribuidores diretos dos serviços aos clientes sofrerão as consequências, referentes à consolidação dos serviços disponibilizados no mercado consumidor, comprometendo todos os parceiros da cadeia produtiva do turismo.

Recomenda-se que, para o bom desempenho dessa relação, baseada no SCM, é importante que as ações entre fornecedores, os sítios turísticos/cidades, os hotéis, transportes, distribuidores e agências estejam bem coordenadas e integradas a fim de que possam fortalecer os elos dessa cadeia, garantindo relacionamentos duradouros e competitivos.

Desenvolvimentos futuros deste estudo devem incluir a participação dos fornecedores dos serviços comercializados pelas agências de viagem e turismo e, além disso, propõe-se averiguar opiniões, atitudes e comportamentos dos consumidores, dentro da cadeia produtiva, a partir de suas percepções sobre a logística e o gerenciamento das relações com os clientes.

Todas essas condicionantes sugerem que o estímulo ao associativismo e a cooperação entre parceiros estratégicos com a criação de redes de distribuição e relacionamentos, pode ser facilitado com a adoção do modelo de gestão SCM de forma a estimular e consolidar a qualificação das pessoas, das empresas e o fortalecimento do setor.

\section{Referências}

ACERENZA, M. A. Agencias de viajes: Organización y operación. México: Trillas, 1990.

ACERENZA, M. A. Promoción turística: um enfoque mercadológico. México: Trillas, 1996.

ASSOCIAÇÃO BRASILEIRA DE AGÊNCIAS DE VIAGENS. Diagnóstico dos fatores críticos da competitividade setorial: agenciamento e operações turísticas. Associação Brasileira de Agências de Viagens, Serviço Brasileiro de Apoio às Micro e Pequenas Empresas. Salvador: ABAV / SEBRAE, 2006.

ANDRADE, J. V. Turismo: fundamentos e dimensões. São Paulo: Ática, 2000.

ARNOLD, J. R T. Administração de materiais: uma introdução. São Paulo: Atlas, 1999.

BALLOU, R. H. Logística empresarial: transportes, administração de materiais e distribuição física. São Paulo: Atlas, 1993.

BENI, M. C. Análise estrutural do turismo. São Paulo: SENAC, 2001.

BOECHAT, Y. A fidelidade se conquista: sedução vai além da milhagem. Gazeta Mercantil, 2001. 
BOGMANN, I. Marketing de relacionamento: estratégias de fidelização e suas implicações financeiras. São Paulo: Nobel, 2000.

CAMPOMAR, M. C.; KHAUAJA, D. M. R. O sistema de informações no Planejamento de Marketing: em busca de vantagem competitiva. Revista de Gestão da Tecnologia e Sistemas de Informação da Universidade de São Paulo, vol. 14, n. 1, 2007.

CARTER, J.R.; PRICE, P.M., Integrated Materials Management. London: Pitman, 1993.

COOPER, C.; FLETCHER, J.; WANHILL, S.; GILBERT, D. e SHEPHERD,

R.Turismo: Princípios e Prática. 2 ed.Porto Alegre: Bookman, 2001.

COOPER, M.C.; LAMBERT, D.M.; PAGH, J.D. Supply chain management: more than a new name for logistics. International Journal of Logistics Management 8 (1), 1-13, 1997.

CHEN, I. J, PAULRAJ, A. P. Towards a theory of supply chain management: the constructs and measurements. Journal of Operations Management 22 (2004) 119-150, 2003.

CHING, H. Y. Gestão de estoques na cadeia de logística integrada - supply chain. São Paulo: Atlas, 1999.

CHIZZOTTI, A. A pesquisa qualitativa e seus fundamentos filosóficos. Pesquisa qualitativa em ciências humanas e sociais, p. 19-31, 2006.

CHRISTOPHER, M. Logística e gerenciamento da cadeia de suprimentos: estratégias para a redução de custos e melhoria dos serviços. São Paulo: Pioneira, 2004.

DALE, B.G., LASCELLES, D.M., LLOYD, A. Supply chain management and development. In: DALE, B.G. (Ed.), Managing Quality. London: Prentice-Hall, 1994. p. 292-315.

DUARTE, D. C. $O$ uso da Internet como estratégia mercadológica: um estudo comparativo entre algumas agências de viagens e operadoras de turismo de São Paulo e Florianópolis. Dissertação (Mestrado em Engenharia de Produção). Universidade Federal de Santa Catarina, Florianópolis, 1998.

FARMER, D. H. Purchasing myopia revisited. European Journal of Purchasing and Supply Management 3 (1), 1-8, 1997.

FARMER, D.H.; VAN AMSTEL, R. Effective Pipeline Management: How to Manage Integrated Logistics. Aldershot: Gower, 1991.

FISHER, M.L. What is the right supply chain for your product?. Harvard Business Review 75 (2), 105-116, 1997.

FORD, D. Understanding Business Markets. London: Academic Press, 1990.

FORRESTER, J. Industrial Dynamics. New York: Wiley, 1961.

GIANNAKIS, M. The history of the development of supply chain management and future direction for building a new academic discipline. In: Proceedings of the European Operations Management Association, 8th International Annual Conference, p.319-332, 2001.

GIL, A. C. Como elaborar projetos de pesquisa. 4. ed. São Paulo: Atlas, 2002.

GORDON, I. Marketing de relacionamento: Estratégias, Técnicas e Tecnologias para Conquistar clientes e mantê-los para sempre. São Paulo: Futura, 1998.

HAKANSSON, H.; SNEHOTA, I. Developing Relationships in Business Networks. London: Routledge, 1995.

HARLAND, C.M.; KNIGHT, L.A. Supply network strategy: role and competence requirements. International Journal of Operations and Production Management 21 (4), 467-489, 2001. 
HELPER, S.R. How much has really changed between US automakers and their suppliers. Sloan Management Review (Summer) 15-28, 1991.

HINES, P. Creating World Class Suppliers: Unlocking Mutual Competitive Advantage. London: Pitman Publishing, 1994.

JARILLO, J.C. Strategic Networks: Creating the Borderless Organization. Oxford: Butterworth Heinemann, 1993.

KOTLER, P. Administração de marketing: análise, planejamento, implementação e controle. São Paulo: Atlas, 1998.

LA LONDE, B.J. Supply chain evolution by the numbers. Supply Chain Management Review 2 (1), $7-$ $8,1998$.

LAMMING, R.C. Beyond Partnership: Strategies for Innovation and Lean Supply. Hemel Hempstead: Prentice Hall, 1993

LEVITT, T. A imaginação de marketing. São Paulo: Atlas, 1985.

MALHOTRA, N. K. Pesquisa de Marketing: uma orientação aplicada. Porto Alegre: Bookman, 2001.

MANZO, J. M. C. Marketing: uma ferramenta para o desenvolvimento. Rio de Janeiro: Livros Técnicos e Científicos, 1996.

MARIEN, E. J. Reverse logistics as competitive strategy. Supply Chain Management Review, vol. 2, n. 1, p. 43-52, 1998.

MARÍN, A. Tecnologia da Informação nas Agências de Viagens: em busca da produtividade e do valor agregado. São Paulo: Aleph, 2004.

MILONE, P. Turismo: teoria e prática. São Paulo: Atlas, 2000.

MINGOTI, S. A. Análise de dados através de métodos de estatística multivariada: uma abordagem aplicada. Belo Horizonte: UFMG, 2005.

MORGAN, J., MONCZKA, R.M. Supplier integration: a new level of supply chain management. Purchasing 120 (1), 110-113, 1996.

NAISBITT, J. China Megatendências: Os oito pilares de uma nova sociedade. Rio de Janeiro: Qualitymark, 2011.

NARUS, J.A., ANDERSON, J.C. Using teams to manage collaborative relationships in business markets. Journal of Business-to-Business Marketing 2, 17-47, 1995.

NOVAES, A. G. Logística e Gerenciamento da Cadeia de Distribuição. Rio de Janeiro: Campus, 2001.

OLIVER, R.K., WEBBER, M.D. Supply Chain Management: Logistics Catches up with Strategy. In:. Christopher, M.G. Logistics: The strategic issue. London: Chapman and Hall, 1992.

PELIZZER, H. A. Planejamento e gestão da hospitalidade no turismo receptivo. In Planejamento e Gestão em Turismo e Hospitalidade. DENCKER, A. F. M. (Coord.). São Paulo: Pioneira Thomson Larning, 2006.

PELIZZER, H. A.; SCRIVANO, N. B. Administração e gerenciamento de agências de turismo. São Paulo: Edicon, 2005.

PIÑOLE, I. A. Gestión y tecnicas de agencias de viajes. Madrid: Sintesi, 2000.

PORTER, M. E. Competitive advantage. New York: The Free Press, 1985.

PORTER, M.E. Managing value-from competitive advantage to corporate strategy. Harvard Business Review 65 (3), 43-59, 1987. 
RUSCHMANN, D. M. Marketing Turístico: Um enfoque promocional. Campinas: Papirus, 2001.

SNOW, C.C., MILES, R.E., COLEMAN Jr., H.J. Managing 21st century network organizations. Organizational Dynamics 20 (3), 5-20, 1992.

THORELLI, H. Networks: between markets and hierarchies. Strategic Management Journal 7 (1), $37-$ $51,1986$.

TOMELIN, C. A. Mercado de Agências de Viagens e Turismo: Como competir diante das novas tecnologias. São Paulo: Aleph, 2001.

TOMELIN, C. A.; TEIXEIRA, A. H. Gerenciamento da cadeia de suprimentos e do marketing de relacionamentos nas agências de viagens. In: TRIGO, L. G. G. Análises Regionais e Globais do Turismo Brasileiro. São Paulo: Roca, 2005.

TORRE, F. Agencias de viajes y transportacion. México: Trilhas, 1990.

WOMACK, J.P., JONES, D.T. From lean production to the lean enterprise. Harvard Business Review $72(2), 93-103$.

WOMACK, J.P.; JONES, D.T., ROOS, D. The Machine that Changed the World. New York: Maxwell Macmillan, 1990.

\section{Recebido em: 05/07/2012 (1ª versão) 18/09/2013 (última versão)}

Aprovado em: 26/09/2013 